\title{
MEMÓRIAS E SEUS SUPORTES: DA FALA À VIRTUALIZAÇÃO E SUAS NECESSIDADES POR PRÓTESES E LUGARES
}

\author{
SPEECH TO VIRTUALIZATION AND THEIR NEED FOR PROSTHESES AND PLACES
}

Mário Gouveia Júnior ${ }^{1}$

\section{RESUMO}

Através deste artigo propomos um debate sobre a importância dos lugares de memória para a sociedade do conhecimento, tributária da velocidade do fluxo de informação e de sua preservação através das novas tecnologias. Concentramo-nos em torno da emergência dos meios digitais e de um suposto desaparecimento dos espaços físicos de memória. Nossas considerações se respaldam e se concentram numa revisão bibliográfica transdisciplinar. Apresentamos como resultado a conclusão de que as necessidades por próteses de memória, em sua natureza tangível, ainda parecem legítimas enquanto forma de determinação e particularização da sociedade e de seus distintos grupos sociais.

\section{PALAVRAS-CHAVE}

Informação. Oralidade. Lugares de memória. Novas tecnologias.

\section{ABSTRACT}

We propose a debate on the importance of places of memory for the knowledge society, dependent on the speed of the flow of information and it's preservation through new technologies. We focus the discussion on the emergence of digital media and an alleged disappearance of the physical memory space. This discussion is based and focuses on a multidisciplinary literature review. We conclude that the need for prosthetic memory, of a material nature, still seem legitimate as a form of identification and individualization of society and social groups.

\section{KEYWORDS}

Information. Orality. Places of memory. New technologies.

\footnotetext{
${ }^{1}$ Mestrando em Ciência da informação pelo Departamento de Ciência da Informação (DCI) da Universidade Federal de Pernambuco (UFPE). Licenciado em História pela Universidade Federal de Pernambuco (UFPE). E-mail: gouveia_historiador@yahoo.com.br.
} 


\section{INTRODUÇÃO}

Diante da extinção de uma memória espontânea (NORA, 1993), há algum tempo, o homem sacralizou lugares com o intuito de resguardar do esquecimento partes de si. Nesse sentido, a ideia de rememorar através do monumento, ou do objeto, ou do lugar sacralizado, sugere o remembramento de nós mesmos. A biblioteca talvez seja o mais antigo desses sítios, onde se confere ao indivíduo a capacidade ou a possibilidade de se deparar com fontes e referenciais identitários que tanto validam quanto conferem sentido a suas práticas e costumes em sociedade.

Múltipla, anacrônica, desacelerada, lacunar, mas nem sempre preenchível pela lembrança particular ou coletiva, a memória, à primeira vista, não parece prescindir de um espaço físico para se processar. No entanto, apesar de estarmos inclinados a assim percebê-la, trazemos no bojo deste trabalho uma inquietação acerca dos chamados lugares de memória: haveria, de fato, essa necessidade de um recinto concreto, dotado de suportes (LE COADIC, 2004) igualmente tangíveis a se enraizar no gesto, na imagem, no objeto (NORA, 1993)?

A demanda pelo tangível como o fármaco mais eficaz no combate ao esquecimento e aos silêncios - que, por vezes, podem denotar reveladores mecanismos de manipulação da memória coletiva (LE GOFF, 2003) - oscilou bastante. Desde a supremacia dos homensmemória, detentores da história objetiva e ideológica de sociedades e grupos ágrafos, passando pelo advento da escrita e do consequente impacto da difusão do invento de Gutenberg (BURKE, 2003), até o emprego das novas tecnologias da informação do século XX, os lugares de memória rumaram da oralidade para os suportes materiais e destes para os virtuais.

Nesse particular em que presenciamos - de modo atuante, inclusive - a chamada explosão quantitativa da informação bem como a implosão do tempo de difusão de seus conteúdos (LE COADIC, 2004), em que plano estariam dispostas a oralidade e as relações sociais nela baseadas? A informação que não está registrada em um suporte representaria, do mesmo modo, um lugar de memória? É importante enfatizarmos que nossa proposta não se destina a antagonizar escrita e oralidade, visto que ambas complementam-se (CERTEAU, 2008b).

$\mathrm{Na}$ primeira parte deste trabalho consideraremos o grau de intangibilidade da memória e a relativa força da oralidade, mesmo nas sociedades urbano-industrial-complexas, e suas raízes coloniais. 
O segundo momento traz a proposta de trabalhar um pouco mais o conceito de lugar de memória. Da mesma forma, abriremos espaço para um breve histórico sobre os lugares de memória no Brasil, desde suas origens, funções e transformações até os novos desafios propostos a essas instituições pela Era do Conhecimento e da Informação.

A terceira parte fomenta um debate acerca da necessidade da existência de um lugar físico para a memória, uma vez que parecemos caminhar para a digitalização e a virtualização de todo o conhecimento. Nessa perspectiva, até certo ponto tornaríamos a dispensar o registro palpável, quando a informação limitava-se às ideias, às cabeças e às bocas, passando ao largo do letramento?

\section{MEMÓRIAS, ORALIDADES E "VERDADES"}

A oralidade, entendida como o espaço essencial de uma comunidade e uma das principais ferramentas da linguagem, faz-se necessária para que exista comunicação, mesmo nas sociedades ditas complexas, onde a escrita se sobrepõe à memorização da tradição e à circulação do saber (CERTEAU, 2008a). Com a invenção da linguagem, por sinal, aos poucos, a humanidade passou a habitar um espaço, que, mediante um imenso conjunto de lembranças e narrativas - datadas ou esparsas - tornou-se virtual ao mesmo tempo em que virtualizou não apenas o tempo real, mas também as coisas materiais e os acontecimentos e situações em curso (LÉVY, 1999).

Desse modo, se assim o podemos chamar, o texto oral, que representa o suporte da memória de um grupo ou de suas produções simbólicas, apesar de ser facilmente emitido por qualquer pessoa que seja capaz de expressar seus sentimentos, vontades e emoções através da fala, foi, no passado, prerrogativa de poucos quando se tratava de contar a história de um grupo, atualizando impressões ou informações de outrora. Tais especialistas eram os homens-memória; capazes de registrar os eventos contemporâneos e lembrá-los à comunidade o ocorrido em épocas pretéritas. Essa é uma forma de poder simbólico (BOURDIEU, 2000), e, como tal, precisa ser reconhecido e legitimado por tais comunidades, que vêem nos homens-memória os bastiões de sua memória.

A manutenção dessas informações, todavia, não se processa nem se transmite num regime rigoroso e engessado do tipo "palavra-por-palavra", mais próximo da escrita. A transmissão oral, atrelada ao gênero narrativo que está, permite mais liberdade e possibilidades e 
variantes criativas (LE GOFF, 2003). É válido anotar, nessa perspectiva, que, muitas vezes, a função dos homens-memória também pode garantir ocultações e esquecimentos inevitáveis à memória individual e coletiva, mas também interessantes às elites no sentido de manter determinada ordem. Isso porque:

Tornar-se senhores da memória e do esquecimento é uma das grandes preocupações das classes, dos grupos, dos indivíduos que dominaram e dominam as sociedades históricas. Os esquecimentos e os silêncios da história são reveladores destes mecanismos de manipulação da memória coletiva (LE GOFF, 2003, p. 422).

Aqueles que controlam os canais de informação, e que se dispõem, de acordo com seus interesses, a construir mitos e editar "a verdade", manipulando-a, são os detentores do que Pierre Bourdieu chamou de poder simbólico - forma de domínio invisível exercido, em parte, a expensas da aquiescência, cumplicidade e submissão da maioria (BOURDIEU, 2000).

Mesmo após o advento da escrita, e sua posterior difusão na modernidade pósGutenberg, o homem continuou a se expressar e a transmitir informações através da fala sobre eventos ocorridos em outras cidades ou na corte, nos centros ou nas periferias. E essa forma de interação predominantemente oral não pode ser explicável apenas em virtude do baixo índice de letramento. Tal discussão, que parece ter raízes coloniais, remete-nos à América portuguesa, no intervalo compreendido entre os séculos XVI e XVIII. Nessa época, apesar de cobiçado por muitos como um objeto conferidor de status social àqueles que o possuíssem, o livro impresso enfrentou sérias dificuldades para ingressar na mais promissora colônia lusitana. Isso porque muitas ideias ali contidas eram temidas por sua natureza libertária - entenda-se anticlerical e antimonárquica.

Como público consumidor desses livros "perigosos", não podemos considerar apenas aqueles que eram capazes de decifrar os códigos escritos, posto que também o povo simples tinha meios de absorver seus conceitos, mesmo sem a capacidade de ler diretamente. Estes ficaram conhecidos como leitores de oitiva numa época em que a alfabetização passava ao largo, a oralidade se expandia e os livros eram mais ouvidos do que vistos, já que esse foi um tempo em que ouvir valia mais do que ver.

É válido lembrarmos, ainda, que essa fórmula de acesso à informação escrita através da leitura de outra pessoa não está nem de longe superada; atualmente, a forma mais popular de transmissão de notícias se dá através da leitura de um locutor de rádio ou repórter de televisão. 
Nesse contexto, as manifestações orais da cultura e da memória popular, contudo, tiveram como adversário implacável a perecibilidade da memória verbal frente ao tempo. A quantidade de informação já não mais era comportada na mente humana; era, então, necessário solucionar o problema do armazenamento de informações em suportes palpáveis e duráveis.

A invenção do alfabeto não apenas possibilitaria à humanidade comunicar ideias através de signos visuais, como também produzir um registro perene destes signos e sinais, e, dessa forma, criar uma memória exterior à mente. Surgia, assim, o que Leibniz chamou de "memória de papel" como soaria menos interessante uma memória vivida coletivamente, já que, haveria cada vez mais a necessidade de homens particulares a fazer de si mesmos homensmemória (NORA, 1993); mais que isso, apareceria a necessidade por lugares de memória.

\section{LUGARES DE MEMÓRIA: DINÂMICAS, BUSCAS E NECESSIDADES}

Um dos principais objetivos da Ilustração, em fins do século XVIII, era fazer do livro uma ferramenta de transformação da sociedade, modelando hábitos através de sua leitura e ditando a substituição das leis consuetudinárias (CERTEAU, 2008a). O oral, dessa forma, juntava-se ao escrito no limiar da modernidade - marco temporal que anunciaria uma época caracterizada pela dilatação dos canais de informação.

Fique claro que com isso não pretendemos reduzir a escrita a um registro da fala (LÉVY, 1999), muito menos definí-la como um procedimento destinado a fixar a palavra como mero meio de expressão permanente. Também não visamos opor a escritura à oralidade - por vezes identificada como elemento que não contribui para o progresso. Pelo contrário; não as percebemos como termos opostos, mas como "o efeito de distinções recíprocas dentro de configurações históricas sucessivas e imbricadas" (CERTEAU, 2008a, p.223).

Essa pretensa evolução da memória escrita foi contemporânea à criação dos primeiros museus etnográficos responsáveis pelo registro, coleção, conservação, transmissão, estudo e interpretação de objetos materiais. Criados na Europa, no século XIX:

(C) Rev. Dig. Bibl. Ci. Inf., Campinas, v.9, n.2, p.64-74, jan./jun. 2012 - ISSN 1678-765X 
aos poucos, os museus etnológicos transformaram-se em depósitos ordenados de uma cultura material fetichizada e submetida a uma lógica evolutiva. Comparar e classificar se tornaram as metas desses cientistas, verdadeiros 'filósofos viajantes', que financiados por instituições científicas dirigem-se a terras distantes em busca de coleções que representem variedades da flora, fauna e da contribuição humana na terra (SCHWARCZ, 1993, p. 69).

No caso brasileiro, é só em 1808, a partir da chegada da família real, que iríamos dispor dos primeiros estabelecimentos ligados à memória escrita, ao documento e ao monumento, como a Imprensa Régia, a Biblioteca Nacional e o Museu Real. Eram nossos primeiros passos enquanto centros produtores e reprodutores de nossa própria cultura e memória, já não mais meros receptores da antiga metrópole (SCHWARCZ, 1993). Vale ressaltar que inicialmente as noções de arquivo, biblioteca e museu estiveram restritas ao mesmo objetivo de servir de depósitos de documentos produzidos pelas práticas humanas em sociedade.

A busca por uma identidade própria, intensificada pelo movimento de Independência de 1822, ainda se estenderia pelo século seguinte; a Semana de Arte Moderna, por exemplo, repercutiria de um modo significativo no sentido de traçar novos rumos para a cultura e para a criação de uma identidade nacional. Do mesmo modo, tais planos integravam as pautas de cientistas sociais e políticos e de governantes.

Novas tecnologias surgidas à época da Segunda Guerra Mundial, sobretudo nos campos da medicina e da informação, propiciaram uma explosão quantitativa associada à implosão do tempo de comunicação, o que permitiu aos estudiosos a constatação acerca da necessidade de dilatação dos campos e canais de geração, coleta e disseminação da informação (LE COADIC, 2004).

Ainda no bojo desse “dilúvio informacional” (LÉVY, 1999, p. 39), graças ao volume de informação produzido espontaneamente pela sociedade, seus meios técnicos de reprodução e de conservação, vivemos na época que mais produziu arquivos (NORA, 1993). Isso porque à medida que a memória tradicional desaparece, somos forçados a acumular sinais visíveis do que foi, criando ambientes artificiais, chamados por Michel de Certeau (2008a) de lugares de expressão e simbolização, ou lugares de memória, posto que não existam mais meios de memória (NORA, 1993). 
Assim, arquivos, bibliotecas e museus se fazem necessários porque não habitamos mais nossa memória, por isso a necessidade de lhe consagrar espaços de produção e divulgação que se enraízam no concreto, no gesto, na imagem, no objeto, materializando-a (NORA, 1993). Esses redutos da memória representam os rituais sagrados de uma sociedade desritualizada e dessacralizada, que só é capaz de lembrar uma ínfima parcela daquilo que poderia ter necessidade de lembrar. É esta uma sociedade que precisa de suportes exteriores e referências tangíveis que possam parar o tempo, bloqueando a ação do esquecimento, imortalizando a morte, materializando o imaterial e prendendo o máximo de sentido num mínimo de sinais (NORA, 1993).

\section{MEMÓRIA DESTERRITORIALIZADA}

Em seus estudos, Pierre Nora (1993) trilhou os caminhos da memória desde a escrita até a alta fidelidade da fita magnética; não acenou para a oralidade nem teceu considerações acerca da virtualização dos lugares de memória. Passadas quase duas décadas desde a referida publicação, temos um ponto ou dois a discutir acerca da imprescindibilidade de um espaço, físico ou não, para o armazenamento das informações de uma sociedade.

Esse debate nos parece legítimo e necessário, posto que, frente à velocidade contemporânea do fluxo de informação, apontada por Le Coadic (2003), caminhamos para uma crescente virtualização da informação, do conhecimento e também da memória. E nessa perspectiva, a invenção de novas velocidades é o primeiro grau de virtualização (LÉVY, 1999). Essas velocidades, diga-se de passagem, não devem ser entendidas como elementos peculiares da modernidade, já que consideramos o advento da escrita, como um significativo insumo que acelerou tanto a exteriorização quanto a virtualização da memória. Assim, cada nova descoberta, cada novo avanço tecnológico representa, em potencial, uma aceleração no caminho de virtualizar a informação e a memória.

Para o senso comum, o termo "virtual" é associado como perfeito oposto de "real", tangível, o que denotaria a inexistência física de tudo aquilo que faz parte do universo virtual. Entretanto Pierre Lévy (1999) salienta que, para a filosofia escolástica, virtual não é o que não existe em ato, mas o que existe em potência, tendendo a atualizar-se sem se concretizar 
efetivamente. Isto posto, a memória digital que armazena uma informação representa o agente operador de uma potencialização desta, enquanto que a realização depende da subjetividade humana através da leitura (LÉVY, 1999). Nesse sentido, a digitalização dispõe diante do leitor um texto móvel, caleidoscópico, que gira, dobra-se e desdobra-se mediante as vontades daquele que o demanda.

Em tempo, o conhecimento ou a informação virtual poderia ser percebido como um devir, que, por um lado necessita de uma ação volitiva e por outro dispensa tempo e lugar de referência para existir, tornando-se não-presente, desterritorializando-se. Contudo essa independência não chega a ser plena, uma vez que os suportes físicos ainda são imprescindíveis. Isso porque: "O suporte digital não contém um texto legível por humanos mas uma série de códigos informáticos que serão eventualmente traduzidos por um computador em sinais alfabéticos para um dispositivo de apresentação" (LÉVY, 1999, p. 39).

Desse modo, parece válida a ideia de que tanto o conhecimento quanto a informação, e a própria memória, não são nem "imateriais" nem "materiais"; são desterritorializados, tendo em vista que não estão restritos a um suporte único, podendo transitar entre eles (LÉVY, 1999). É dessa forma que até mesmo os bens classificados como materiais são medidos, observados e classificados através de suas dimensões imateriais - formas, estruturas e propriedades em contexto.

No tocante às necessidades por lugares de memória postuladas por Pierre Nora cabe a nós considerarmos que mesmo vivendo numa era de crescente digitalização e virtualização continuam a existir e se fazerem necessários sítios de inscrição material. Tais espaços virtuais ganham significação enquanto suportes de informação, passando a existir de fato mediante os imperativos daqueles que os demandam. Não basta, todavia, ao homem contemporâneo mergulhar nesse mundo de possibilidades da Web ao sabor dos ventos do hipertexto. Antes de sabermos as respostas, precisamos estar conscientes de quais perguntas devem ser feitas. A memória é, assim, entendida como um campo de negociação onde devemos deixar de lado a oposição entre a objetividade e a subjetividade para, daí, colhermos os seus melhores frutos. 
Diante das maravilhas propiciadas no campo da comunicação e da informação à distância, muitos são os que vaticinam o fim das instituições memoriais físicas. A responsabilidade por tamanha tragédia não seria apenas o advento das tecnologias digitais, visto que, para além de toda a comodidade do consumo de um livro ou uma obra de arte na segurança e no conforto do lar do usuário, há que se considerar as próprias carências e deficiências de determinados equipamentos culturais.

Desse modo, percebemos como equivocadas as instituições que sacralizam os acervos de modo a dificultar o livre acesso, todavia condená-las ao futuro certo do desaparecimento nos parece uma atitude determinista.

É assim que entendemos que, se por um lado, através da intensificação das tecnologias advindas do novo paradigma do elétron, caminhamos, ao menos aparentemente, para uma espécie de retorno à ausência de registros palpáveis, por outro estamos inclinados a acreditar que nesse admirável mundo novo os suportes de memória se transformam ao sabor dos avanços científicos, mas ainda fundamenta-se a existência de lugares de memória.

\section{CONSIDERAÇÕES FINAIS}

Neste artigo buscamos apresentar, ainda que brevemente, as noções de memória e a variabilidade de seus suportes ao longo do tempo. Contemplamos, inicialmente, o tempo em que o homem começou a organizar-se em comunidades regidas por leis baseadas nos costumes. Nessa época, os homens-memória selecionavam e registravam eventos, ditando costumes e inventando tradições.

Discutimos, também, que a oralidade ainda está, de certo modo, presente na realidade contemporânea de sociedades extremamente complexas e que têm nos registros tangíveis seu eixo norteador. As sociedades ágrafas tinham as "cabeças" e as "bocas" como suportes de memória - posto que o suporte, qualquer que seja ele, denota, necessariamente, as funções de registro e disseminação da informação.

Trouxemos, do mesmo modo, o conceito de lugares de memória e a ideia da atual inexistência dos meios de memória propostos por Pierre Nora. Nesse sentido, por não mais termos a capacidade de comportar o conhecimento mínimo para desempenharmos nossos papéis

(C) Rev. Dig. Bibl. Ci. Inf., Campinas, v.9, n.2, p.64-74, jan./jun. 2012 - ISSN 1678-765X 
sociais, e não mais termos vivos em nossa mente os nossos referenciais identitários, foram criadas instituições que preservam tais valores. Arquivos, bibliotecas e museus, nos últimos séculos, têm, minimamente, dado conta do registro, armazenamento, recuperação e disseminação da cultura e da memória das sociedades.

Diante da emergência de novos suportes virtuais, apresentamos indagações sobre a demanda pela existência de um espaço físico para uma memória cada vez mais múltipla, caleidoscópica, liquída, até. Pierre Lévy nos conferiu a consciência de que virtual e real não se antagonizam, e que escrita e linguagem não são sucedâneos da virtualização, mas dois grandes instrumentos dessa virtualização. Ademais, a virtualidade não faz parte de um mundo falso ou imaginário, e sim de uma dinâmica através da qual compartilhamos uma realidade.

Percebemos, afinal, que as necessidades por lugares de memória, por próteses de memória, ainda parecem legítimas, posto que, independente da natureza do suporte - material, imaterial, oral, icônico, escrito ou virtual - se fazem necessários os espaços de consagração e manutenção dos feitos humanos em sociedade que determinam e particularizam seus grupos.

Nesse particular, defendemos a assunção de bibliotecas e museus enquanto espaços de vida, espaços dinâmicos, tais como a própria lógica das sociedades humanas, que sempre se reinventam. É dessa forma que, acreditamos, as novas concepções de biblioteca e museu podem fomentar no usuário a vontade de estar naqueles lugares a despeito das possibilidades remotas conferidas pelo universo digital.

\section{REFERÊNCIAS}

BOURDIEU, P. O poder simbólico. 3.ed. Rio de Janeiro: Betrand Brasil, 2000.

CERTEAU, M. A invenção do cotidiano: 1. Artes de fazer. 15.ed. Petrópolis: Vozes, 2008a. Vozes, 2008 b.

; GIARD, L.; MAYOL, P. A invenção do cotidiano: 2. Morar, cozinhar. 7.ed. Petrópolis:

LE COADIC. Y.-F. A ciência da informação. 2.ed.rev. e atual. Brasília: Briquet de Lemos, 2004.

LE GOFF, J. História e memória. 5.ed. Campinas: UNICAMP, 2003.

LÉVY, P. O que é virtual? São Paulo: Editora 34, 1999.

(C) Rev. Dig. Bibl. Ci. Inf., Campinas, v.9, n.2, p.64-74, jan./jun. 2012 - ISSN 1678-765X 
NORA, P. Entre memória e história: a problemática dos lugares. In: PROJETO HISTÓRIA: Revista do Programa de Estudo Pós-Graduados em História e do Departamento de História da PUC-SP. n.10. São Paulo, 1993.

SCHWARCZ, L. M. O espetáculo das raças: cientistas, instituições e questão racial no Brasil 1870-1930. São Paulo: Companhia das Letras, 1993. 